\title{
Variable Seed Bed Microsite Conditions and Light Influence Germination in Australian Winter Annuals
}

Isaac Ray Towers ( $\sim$ i.towers@uq.edu.au )

The University of Queensland School of Biological Sciences https://orcid.org/0000-0003-4570-3474

David J Merritt

Western Australia Department of Biodiversity Conservation and Attractions

Todd E Erikson

Western Australia Department of Biodiversity Conservation and Attractions

Margaret M Mayfield

The University of Queensland School of Biological Sciences

John M Dwyer

The University of Queensland School of Biological Sciences

\section{Research Article}

Keywords: photoblasticity, spatial coexistence, York gum - jam, dormancy, Mediterranean

Posted Date: April 14th, 2021

DOI: https://doi.org/10.21203/rs.3.rs-312523/v1

License: (c) (1) This work is licensed under a Creative Commons Attribution 4.0 International License. Read Full License

Version of Record: A version of this preprint was published at Oecologia on January 9th, 2022. See the published version at https://doi.org/10.1007/s00442-021-05091-7. 
1 Title: Variable seed bed microsite conditions and light influence germination in Australian

2 winter annuals

3 Article type: Highlighted student research

4 Isaac R. Towers ${ }^{1,2}$, David J. Merritt, ${ }^{3,4}$, Todd E. Erickson ${ }^{4,3}$, Margie M. Mayfield ${ }^{1}$ and John $5 \quad$ M. Dwyer ${ }^{1}$

$6 \quad{ }^{1}$ The University of Queensland, School of Biological Sciences, Australia, 4072

$7 \quad{ }^{2}$ Corresponding author: $\underline{\text { i.towers @uq.edu.au }}$

$8{ }^{3}$ School of Biological Sciences, The University of Western Australia, Crawley, Western

9 Australia, Australia

$10{ }^{4}$ Kings Park Science, Department of Biodiversity, Conservation and Attractions, Western

11 Australia, Australia

12 Running title: Microsite conditions and light influence germination in winter annuals

13 Highlighted Student Paper Justification: This research advances our understanding of the role

14 that seed bank dynamics play in spatially heterogenous ecosystems by teasing apart the

15 influence of microsite conditions on germination fractions

\section{Declaration of authorship}

17 I. R. Towers, D. E. Merritt, T.E. Erikson, J. M. Dwyer and M. M. Mayfield contributed significantly to the conception and design of the project conducted in Chapter 3. Data in

19 Chapter 3 was collected by I. R. Towers. I.R. Towers analysed the data and wrote the first 20 draft of the manuscript. I. R. Towers, D. E. Merritt, T.E. Erikson, J. M. Dwyer and M. M.

21 Mayfield contributed significantly to the interpretation of results and critical revision of the

22 work in Chapter 3. 


\section{Abstract}

24 Environmentally-cued germination may play an important role in promoting coexistence in

25 Mediterranean annual plant systems if it causes niche differentiation across heterogenous

26 microsite conditions. In this study, we tested how microsite conditions experienced by seeds

27 in the field and light conditions in the laboratory influenced germination in twelve common annual plant species occurring in the understorey of the York gum-jam woodlands in southwest Western Australia. Specifically, we hypothesized that if germination promotes spatial niche differentiation then we should observe species-specific germination responses to light. In addition, we hypothesized that species' laboratory germination response may depend on the microsite conditions experienced by seeds while buried. We tested the laboratory germination response of seeds of species under diurnally fluctuating light and complete darkness which were retrieved from microsites spanning local-scale environmental gradients known to influence community structure in this system. We found that seeds of six out of the twelve focal species exhibited significant positive germination responses to light but that the magnitude of these responses varied greatly. In addition, maximum germinability increased significantly across a gradient of canopy cover for two species, but we found little evidence to suggest that species' relative light requirement for germination varied depending on microsite conditions. Our results suggest that variability in light availability may promote coexistence in this system and that the microsite conditions seeds experience in the intragrowing season period can further nuance species germination behaviour.

\section{Keywords}

44 photoblasticity, spatial coexistence, York gum - jam, dormancy, Mediterranean

\section{Introduction}


Mediterranean-climate regions are characterized by hot, dry summers and cool, wet winters, and support disproportionally high levels of global vascular plant diversity relative to their land area (Kreft and Jetz 2007). Plant species in these regions typically exhibit an ecological

49 strategy which permits them to either avoid or tolerate seasonal droughts (Bernhardt 2007). For example, winter annual plants, which are a significant component of the diversity in Mediterranean ecosystems, capitalize on the winter months throughout the vegetative phase of their life cycle and avoid unfavourable conditions during the dry summer months as seeds in the seed bank (Cowling et al. 1996). Environmentally-cued germination is an important adaptation to the life cycle of annuals plants to ensure that the transition between seed and germinant occurs when the environment is most favourable for post-germination survival and growth (Donohue et al. 2010, Baskin and Baskin 2014a).

Seed dormancy and germination traits cue seed recruitment to the right time of year (Gremer et al. 2016), but recruitment from the seed bank is also known to vary spatially, depending on local microsite conditions (Rice 1985, Facelli et al. 2005). Indeed, spatial variation in species' seed germination is often invoked to explain how diversity is maintained in ecological communities because it is another axis along which species can partition their niches (James et al. 2020; Chesson 2000b). Fundamentally, this partitioning depends on seeds of different species exhibiting unique germination behaviour in response to different microsite conditions.

Light availability is one the major environmental factors that is perceptible by seeds and is often required to elicit germination in annual plants (Grime et al. 1981, Scott and Morgan 2012). However, the effect of light on the probability of germination is not consistent across species or ecosystems. On one hand, many studies have shown that a greater fraction of small-seeded species, in particular, tend to germinate under light rather than dark conditions (i.e. positive photoblasticity; Grime et al. 1981, Plummer and Bell 1995, Morgan 1998, 
Milberg et al. 2000, Scott and Morgan 2012, Baskin and Baskin 2014b), presumably as an adaptive strategy to prevent germination when seeds are buried deep in soil or under dense leaf litter where seed energy reserves are insufficient for successful emergence. On the other hand, in arid and semi-arid environments, increased germination in the dark is frequently reported (i.e. negative photoblasticity; Thanos et al. 1991, Schütz et al. 2002, MirandaJácome et al. 2013) and may be important to ensure that germination occurs in microsites where harsh solar irradiation is attenuated by nurse plant coverage, or to prevent germination on a rapidly drying or impenetrable soil surface (Bell et al. 1995). Finally, seeds may be insensitive to light availability (neutral photoblastic; Flores et al. 2015). Differential photoblastic responses across species within a single ecological community are known to occur and may play a role in promoting spatial niche separation (Scott and Morgan 2012). Investigating variation in seed sensitivity to light amongst species in different ecological communities can improve our understanding of how light availability influences seed bank dynamics which, in turn, may have important consequences for our mechanistic understanding of species coexistence in spatially varying environments (Chesson 2000a).

Species' seed germination responses may also be dependent on the microsite conditions individuals experience after dispersal (i.e. seed bank conditions). Many winter annual plant species are physiologically dormant after shedding from the mother plant and cannot germinate until dormancy is alleviated (Baskin and Baskin 2014a). Seed dormancy alleviation is influenced by abiotic conditions such as temperature and moisture availability (Schütz et al. 2002) which may vary even across local scales and thus influence spatial variation in dormancy depth within seed populations (Dwyer and Erickson 2016, Kaur et al. 2020). This may, in turn, lead to more nuanced post-emergence site selection by species if the microsite conditions which most effectively alleviate dormancy are decoupled from those which promote germination. 
In this study, we test the light requirements for seed germination in vitro for twelve common annual plant species occurring in the understory of York gum-jam woodlands in southwest Western Australia. This woodland is characterized by a sparse overstorey of Eucalyptus loxophleba (York gum) and Acacia acuminata (jam) which leads to natural variation in patch conditions such as the amount of shade and leaf litter as well as scattered woody debris. Thus, in addition to testing light sensitivity for germination, we also tested how variation in seed bank conditions influenced germination responses amongst species. In contrast to many studies which simulate variation in the seed bank environment under laboratory conditions, our aim in this study was to test species' germination after experiencing natural, field-based variation in seed bank conditions. As such, we assessed whether microsite conditions experienced in the seed bank in situ are associated with variation in: i) species' maximum germinability and ii) the magnitude of species' germination responses to light relative to complete darkness.

\section{Methods}

Study system and species

Winter annual plants in the York gum-jam woodlands germinate following the onset of cool, wet conditions at the beginning of winter (June) and set seed in spring (October-November). Dispersed seeds spend the hot, dry summer-autumn period in the seed bank. Experimental work was conducted in the West Perenjori nature reserve $\left(29^{\circ} 28^{\prime} 40^{\prime \prime} \mathrm{S}, 116^{\circ} 12^{\prime} 00^{\prime \prime} \mathrm{E}\right.$, close the most northern extent of the York gum - jam woodlands. Germination inducing rainfall in June averages $57 \mathrm{~mm}$, and daily minimum and maximum temperatures in June average $7.6^{\circ} \mathrm{C}$ and $19.3^{\circ} \mathrm{C}$, respectively (Bureau of Meterology 2020). We selected 12 focal species which are common across the reserve and that exhibit considerable variation in seed mass. Focal species represented five different families and 11 different genera (Table 1). 
Seeds of each focal species were collected in early October 2018 from mother plants across a variety of environmental patches in the reserve and were combined to control for possible effects of local adaptation and maternal effects. To expose the collected seeds to natural conditions in the soil seed bank, at the end of the 2018 growing season (early-mid October), we buried 50 intact and filled seeds of each species in twenty different locations across the reserve. Burial locations (patches) were systematically selected to capture measurable variation in different aspects of the abiotic environment known to be strongly associated with annual plant species turnover in this system (i.e. canopy cover, litter cover and the presence of coarse woody debris [CWD]).

Prior to being buried, seeds were separated from chaff and placed into thin nylon mesh bags mixed with $20 \mathrm{~mL}$ of coarse sand to reduce seed-seed contact and associated risks of pathogen-related mortality (Van Mourik, Stomph \& Murdoch 2005). One row of 12 filled bags (i.e. one per species) was buried to a depth of $1 \mathrm{~cm}$ in each patch ( $240 \mathrm{bags}$ total; 12 species $\mathrm{x} 20$ patches) such that seed bags were just covered by topsoil. If coarse woody debris was present, the row of seed bags was buried immediately adjacent and parallel to the debris to ensure all species experience similar conditions. In patches where leaf litter was present, it was carefully removed from the area in which the seed bags were to be buried and replaced after the seed bags were in position.

Seed bags were retrieved in mid-May 2019 just prior to the onset of germination-inducing rainfall and transported to the laboratory at Kings Park and Botanic Garden, Perth, Western Australia.

Seed bank environmental conditions

143 Canopy cover was measured by taking an upwards-facing wide-angle digital photograph 
patch. The percentage of overhead canopy cover was estimated from the digital photographs using ImageJ (Schneider et al. 2012). The presence of leaf litter was recorded as a binary variable where a "presence" was recorded if the entire row of seed bags was covered such that little to no surface soil was visible. Similarly, the presence of CWD was recorded as a binary variable.

\section{Germination experiment}

Prior to conducting the germination experiment, seed fill (a proxy for viability) for each species was assessed on seeds retrieved from each patch using X-ray examination (Faxitron MX-20 digital X-ray cabinet, Tuscon, Arizona, USA). Under X-ray, a filled viable seed appears uniformly white/grey in the imagery as they contain a healthy endosperm and embryo. Non-filled seeds tend to have clear abnormalities, fractures and dark shading and are deemed non-viable.

The germination test was conducting by randomly dividing the seeds for a given species and patch into two equal groups. In a few cases, some seeds were lost from the mesh bag prior to the start of the experiment so that the total number of seeds across both groups was less than 50. There were no obvious signs that germination had occurred in any of the mesh bags prior to extraction from the field. Each group of seeds was placed on a sheet of filter paper moistened with 10mL/L Plant Preservation Mixture (Plant Cell Technology, Washington D.C.) in a Petri dish and wrapped in clingwrap to prevent moisture loss. One Petri dish from each mesh bag was randomly assigned to the "dark" treatment and was wrapped in aluminium foil twice to completely prevent light penetration while the other petri dish was assigned to the "light" treatment and was left unwrapped. Application of the dark treatment occurred immediately after the moistening of filter paper to avoid imbibition in the presence 
of light. Thus, in total, there were twenty paired replicates of the light/dark treatment for each species (i.e. 40 Petri dishes per species).

Petri dishes across both treatments were randomly assigned a position inside a single growth cabinet. Light was provided by cool white, fluorescent tubes $\left(30 \mu \mathrm{mol} \mathrm{m}{ }^{-2} \mathrm{~s}^{-1}, 400-700 \mathrm{~nm}\right)$ with a 12/12 h day/night regime. The temperature regime inside the growth cabinet was a $12 / 12 \mathrm{~h}$ diurnal cycle of $19^{\circ} \mathrm{C}$ (during the day) and $7^{\circ} \mathrm{C}$ (during the night) to mimic average maximum and minimum daily temperatures during peak germination at Perenjori (Bureau of Meterology 2020). Germination in the light treatment was scored every $7 \mathrm{~d}$, beginning $7 \mathrm{~d}$ after the experimental trial was conducted, for $35 \mathrm{~d}$. During each inspection, seeds were recorded as germinated when the radicle emerged from the seed coat, and were removed after counting. It was not possible to inspect germination in the dark treatment through time and so germination was instead inspected only at the end of the 35-day period. All Petri dishes were re-randomised within the growth cabinet after each seven-day interval.

Overall, seed fill was high for all species (>90\%) and was mostly unresponsive to measured environmental variables (Table S1). Nevertheless, we adjusted germination percentages for each species to account for seed fill by multiplying the total number of seeds in each Petri dish by the species and patch-specific seed fill fractions obtained from X-ray analysis (rounding up to the next whole number). In addition, individuals which had broken their seed coat but either had no radicle or an unhealthy-appearing radicle were considered non-viable and were subtracted from the total number of viable seeds in each Petri dish.

\section{Statistical analyses}

All statistical analyses were conducted in R Version 4.0.3 (R Core Team 2020) via RStudio Version 1.3.1093 (RStudio Team 2020). We used a Bayesian framework for statistical modelling. Bayesian models were fitted in Stan (Carpenter et al. 2017), via the brms package 

iterations and a burn-in of 1500 iterations. Because we used the default, weakly informative prior distributions when estimating regression coefficients and variance parameters in brms, the central tendencies of posterior distributions are analogous to the parameter estimates obtained from generalised linear models using frequentist methods. We assessed the $\mathrm{R}^{\wedge}$ statistic to evaluate model convergence where $\mathrm{R}^{\wedge}<1.1$ was considered to indicate adequate model convergence (Gelman and Rubin 1992). Parameter estimates were interpreted as being "significant" when the $95 \%$ credible interval of the posterior distribution did not bound zero.

To first assess the overall effect of the light treatment on germination, mixed-effects binomial models were used to assess the probability of a seed germinating in either light or dark conditions for each species. Patch was included as a random intercept. Petri dish was also included as a random intercept, as observation-level random effects to account for overdispersion (Elston et al. 2001). Relative light germination (RLG) was then expressed for each species, $s$, using the point estimates from the posterior distribution of the estimated parameters for probability of germination in the light, $G_{\text {light }}$ and in the dark, $G_{d a r k}$ :

$$
R L G_{s}=G_{\text {light }} /\left(G_{\text {light }}+G_{\text {dark }}\right)
$$

Where values of RLG greater than 0.5 indicate greater germination in the light than in the dark and vice versa for values of RLG lower than 0.5 (Milberg et al. 2000).

To assess the effect of patch conditions on species' germination responses, we first tested how species' maximum germinability varied across patches. In this case, maximum germinability was considered to be the Petri dish (i.e. light or dark treatment) for each patch which had the highest percentage of germination. Patch-level maximum germination was then regressed as a function of the measured environmental variables using mixed-effects binomial models, including Petri dish as a random intercept. The environmental variables 
included in these models were the percentage of overstorey canopy cover and the presence of coarse woody debris. Overstorey canopy cover and the presence of leaf litter on the seed bags were strongly and positively correlated so we chose to omit the presence of leaf litter to improve the interpretability of models.

The effect of seed bank conditions on species' germination response to light was then assessed by regressing the probability of germination across all Petri dishes as a function of the light/dark treatment, each environmental variable and their two-way interaction. Again, a mixed-effects binomial model was used, including patch and Petri dish as nested random intercepts. In cases where a statistical interaction was significant, we used the emtrends and emmeans functions in the emmeans package (Lenth 2020) to estimate the marginal mean slope of the effect of the environmental variable on the probability of germination under light and dark conditions separately.

\section{Results}

Mean seed fill across all patches ranged from 91\% (A. calendula) to 97\% (T. ornata; Figure $1)$.

\section{Species overall germination responses to light vs. complete darkness}

Six out of the twelve species exhibited significant germination responses to the light treatment, and in all these cases, they were positive (Figure 1). However, the relative magnitudes of these significant responses were highly variable, with RLG ranging between $\sim 51 \%$ (D. glochidiatus) and $\sim 86 \%$ (V. rosea; Table 1). Only one species, A. calendula, exhibited a negative response to light, however, the effect was not significant. Germination was observed under light and dark conditions for all species. 
There was substantial variation in the medians of species-level maximum germinability, ranging from $25 \%$ for T. ornata to $100 \%$ for D. glochidiatus, G. berardiana and H. glabra (Table 2). Of the two environmental variables measured in the seed bank locations, species' maximum germinability responded most strongly to the amount of overstorey canopy cover, where $P$. aristata and $T$. ornata had significantly lower germination as the amount of canopy cover increased (Figure 2). The presence of CWD had no effect on maximum germinability for any species.

Seed bank microsite conditions and species' germination responses to light vs. complete darkness

There was only one statistically significant interaction between the effect of the light treatment and the measured seed bank conditions out of the twelve focal species studied (Table 3). This interaction indicated that the probability of germination for G. berardiana declined with canopy cover under dark germination conditions but increased with canopy cover under light germination conditions (Figure S1). However, post-hoc regression of germination probability across canopy cover for G. berardiana revealed that the germination $\sim$ canopy cover slopes were not significantly different from zero under either incubation condition (slope value and credible interval under light in logits $=0.91[-0.17,1.98]$, slope value and credible interval under dark in logits $=-0.25[-0.73,0.25])$.

\section{Discussion}

We report the germination response of 12 winter annual species from a semi-arid woodland in the context of variation in seed bank conditions as dictated by differing canopy cover, leaf litter, and scattered woody debris. Seed populations of half of the species exhibited significant, positive responses to exposure to light in their germination fractions, although the magnitude of these responses varied considerably between species. Spatial variation in 
canopy cover above the seed bed was found to influence maximum germinability for two

264

265

266 species; although only seeds of one of these species, $T$. ornata, responded significantly in its germination to both the amount of canopy cover and light treatment. There was only minor evidence to suggest that seed bank conditions may also influence species' relative response to light and dark conditions (Table 3).

\section{Light requirements for germination}

Six out of the 12 focal species exhibited significant positive germination responses to light, suggesting that positive photoblasticity is a relatively common phenomenon in our study system. This finding is consistent with a number of other studies (Bunker 1994, Plummer and Bell 1995) in Australian annual plant systems including Scott and Morgan (2012) who found that 15 out 19 species of forbs from a south eastern temperate grassland had higher germination under light than continuous darkness. In contrast to a number of other studies in semi-arid and Mediterranean environments (Thanos et al. 1991, Schütz et al. 2002, MirandaJácome et al. 2013), however, we found very little evidence for negative photoblasticity (i.e. higher germination in the dark). Schütz et al. (2002) hypothesised that light-inhibited germination should be more common in Mediterranean ecosystems where germination on the soil surface is risky due to rapid loss of surface soil moisture. Counter to this expectation, our results suggest that light-sensitive species instead germinate most readily in microsites and soil depths where light is readily available.

Seed mass is hypothesised to have coevolved with species' germination requirement for light as an adaptive strategy to ensure that smaller seeds, which have less maternal provisioning, germinate when close to the soil surface or in open microsites (Grime et al. 1981, Milberg et al. 2000). Interestingly, after conducting further regression analysis, we found that largerseeded species instead tended to exhibit stronger, positive germination responses to light than 
smaller-seeded species, although this relationship was weak (Figure S2; Table S2). Given the relatively small number of focal species and plant families that we studied, and the fact that we did not observe species with significantly higher germination under dark conditions, it is not possible to infer whether this pattern is more broadly applicable to our system.

Nevertheless, it does support the presence of a wide variety of germination strategies in our system including large-seeded species with strong requirements for light (Rojas-Aréchiga et al. 2013). In turn, this suggests that the adaptive value of strong light requirements for germination may extend beyond ensuring that individuals have sufficient seed resources to successfully emerge in our system and could be further investigated by assessing the relationship between photoblasticity and traits relevant to later life stages (Donohue et al. 2010). For example, it may be that sensitivity to light operates as a gap-detecting mechanism which promotes germination in open or bare microsites and would be selected for if species possessed traits which conferred a high probability of post-establishment success in these microsites. It is also possible that seeds depend on other environmental cues in addition to or instead of light to indicate depth of burial. For example, in Mediterranean annuals, Saatkamp et al. (2011) showed that seeds of some species require diurnal fluctuations in temperature to germinate and proposed that this may have adaptive value as a depth-sensing mechanism because the magnitude of diurnal fluctuations in temperature decrease with depth. Exploring the relationship between seed size and the interactive effect of sensitivity to fluctuations in germination temperature and light would therefore be of significant value in this system.

Seed germination responses to light conditions can be complex and are known to vary with seed dormancy status (Derkx and Karssen 1993) and other seasonally varying environmental factors including temperature and the chemical environment (Merritt et al. 2006, Karlsson and Milberg 2007). It is therefore important to acknowledge that our germination assay captures only a "snapshot" of the possible phenotypic variation in light/dark response of the 
retrieved seeds. Nevertheless, the temperature regime in the growth chamber was selected to simulate the climatic conditions experienced by seeds in a typical early winter (beginning of the growing season) in the northern extent of the York gum-jam woodlands and as known as conducive to germination of annuals from this region (Merritt et al. 2006). In addition, seeds were permitted to over-summer in the field to promote dormancy loss via after-ripening (Schütz et al. 2002). Thus, observed photoblastic responses are most likely consistent with "average" patterns in the field.

\section{Seed bank conditions}

The abiotic environment experienced by seeds after dispersal from the mother plant is known to influence the depth of dormancy in annuals plants in a variety of systems (Bouwmeester and Karssen 1989, Derkx and Karssen 1993, Schütz et al. 2002) In this study, it was not possible to definitively determine whether seeds exhibited primary dormancy as germinability was not assessed on freshly dispersed seeds. Nevertheless, our study species include genera and families known to produce seeds with physiological dormancy (Asteraceae, Goodeniaceae) or morphological dormancy (Apiaceae, Trachymene) (Schütz et al. 2002, Hoyle et al. 2008, Hidayati et al. 2019) and we found that maximum germinability for at least two species varied significantly between our seed bank conditions. Thus, after accounting for minor variation in seed viability, this provides evidence to suggest that seeds of at least some species do exhibit dormancy and that their spatial position in the landscape influences dormancy alleviation. Indeed, germination tests on freshly-dispersed seeds from a different growing season indicate that all focal species exhibit primary dormancy, corroborating this conclusion (Arend da Silva et al. unpublished data). Across of the remainder of our focal species, however, it seems that variation in burial conditions had only weak effects on germinability, at least within the range of environmental variables that we measured. 
Maximum germinability varied most strongly in response to seed bank overstorey cover for two species. This was effect was consistent across species where germinability decreased for both $P$. aristata and $T$. ornata as canopy cover increased. Previous studies of seeds with physical dormancy have shown that germination fractions are higher when seeds are retrieved from open microsites compared to shaded microsites, most likely due to higher rates of seed coat softening (seed permeability) in open microsites (Vázquez-Yanes and Orozco-Segovia 1982, Rice 1985, Jaganathan 2018). However, we are aware of few studies in other systems investigating the effect of in situ burial under canopy cover for seeds which likely exhibit physiological dormancy (but see Dwyer and Erickson 2016). In our system, canopy cover is known to reduce the maximum temperature at the soil surface as well as the amplitude of diurnal temperature fluctuations (Dwyer and Erickson 2016). Our findings for P. aristata and temperatures both in situ and in vitro tend to alleviate dormancy in annual plants with physiological dormancy (Schütz et al. 2002, Dwyer and Erickson 2016). Interestingly, the presence of CWD, which is also known in other systems to reduce temperature fluctuations, reduce the rate of soil moisture loss and influence the soil chemical environment (Gray and Spies 1997, Goldin and Hutchinson 2013, 2014), did not exert strong effects on maximum germinability in our species, despite the fact that these environmental factors are well known to influence the alleviation of dormancy in other ephemeral species (Schütz et al. 2002, Baker et al. 2005, Merritt et al. 2006).

Seed germination response to light is known to depend in some cases on other presiding environmental factors prior, during and following imbibition (see Pons 2013 and studies cited within). Ultimately, we found little evidence to suggest that seed bank conditions influence the relative light requirement for seed germination, except in the case of $G$. berardiana. For this species, germination in complete darkness showed a weak negative trend with seed bank 
canopy cover increased, whereas germination in the light treatment was very high regardless of the seed bank conditions. However, post-hoc analysis of the effect of canopy cover for the light and dark data separately revealed that neither slope was significant, suggesting that the difference between the slopes was relatively minor. Few studies, if any, have addressed how variation in the seed bank conditions which we chose to measure influences species' germination response to light so it is unclear whether our findings are consistent with those from other systems. For laboratory-stored seeds of some southwest Western Australian annuals, Schütz et al. (2002) found that the relative proportion of seeds germinating under light or dark conditions changed for Podotheca gnaphalioides depending on the temperature of dry storage. However, the temperature of storage in this case was between $5^{\circ} \mathrm{C}$ and $25^{\circ} \mathrm{C}$ which likely captures a wider, and cooler, range of temperatures than what seeds would have experienced in the seed bank. Thus, it may be in our study that we captured insufficient variation in important environmental conditions across the different patches to induce changes in seed light sensitivity.

Ecological consequences of species' seed germination response

Median maximum germinability varied significantly across species with all, or almost all, seeds of some species (i.e. D. glochidiatus, H. glabra) germinating but a number of species (i.e. A. calendula, $P$. aristata, $T$. cyanopetala, $T$. ornata) typically germinating to less than $50 \%$, even under ostensibly favourable conditions, suggesting that seeds may have remained dormant. In winter annual plants, dormancy is an evolved "bet-hedging" strategy which spreads the risk of germination across multiple growing seasons (Finch-Savage and LeubnerMetzger 2006, Gremer and Venable 2014). The trade-off of prolonged dormancy and persistence in the seed bank is that seeds experience a greater likelihood of predation or pathogen-related disease with time (Mittelbach and Gross 1984, Van Mourik et al. 2005). 
strategy, seeds of the other species with a more risk-averse germination strategy still likely depend on the accumulation of multi-year seed banks, with differing degrees of dormancy depth, for population persistence. Seed fill was generally high for all species after one summer in the seed bank, but testing persistence in the seed bank, along with dormancy status and germinability across multiple years, and in the presence of seed predators, would yield further insight into the variation in regeneration strategies amongst species.

Species-specific germination strategies may promote coexistence if it causes species to partition their niches across space. In our case, we observed at least two germination syndromes in response to light, being either neutral or positive photoblasticity. Amongst the positive photoblastic responses, however, species appeared to be differentiated depending on the magnitude of their response. For example, species such as G. berardiana, L. rosea and $V$. rosea exhibited an "all-or-nothing" response to light with correspondingly high RLGs (i.e. > 0.80). In contrast, the effect of light on the remaining positively photoblastic species was substantially more reserved, especially in the case of $D$. glochidiatus which had an RLG of 401 just 0.51 . Taken as a whole, these results suggest that niche separation across spatial gradients of light availability may occur not only through the direction of seed photoblasticity but also through its magnitude. In addition, although it was not in the scope of the present study, it is possible that differences between species' germination strategies may also emerge in response to the duration of light exposure. For example, Milberg and Andersson (1997) found that germination under light differed for seeds of some annual species depending on whether they were exposed to light for only five seconds or for the entire incubation period. This phenomenon warrants further investigation in our system given the strong light responses that we have already observed (Milberg and Andersson 1997). 
412 or cool) where seeds were buried throughout the summer monthsas well as the germination

413 temperature, thereby showing that temperature can mediate cumulative germination fractions

414 through its influence on multiple stages of seed life history. In a similar way, our finding that

415 maximum germination rates varied in a species-specific manner across a gradient of canopy

416 cover points to a complex effect of the spatial environment whereby germination rates are

417 determined not only by seed bank conditions coinciding with the arrival of germination-

418 inducing rainfall (i.e. the light treatment) but also with those occurring throughout the

419 summer (Kaur et al. 2020). Ultimately, this phenomenon may facilitate more nuanced site

420 selection by species, promoting coexistence through niche separation, although this will

421 require further investigation.

\section{Acknowledgements}

423 Thanks go to the Perenjori Shire Council, Western Australia for accommodating our research

424 team, the WA Government for permitting access to the West Perenjori Nature Reserve and

425 David Symons and Alexandra Catling for technical assistance with the germination and

426 viability testing. Thanks also go to Abigail Pastore and Catherine Bowler for assistance with

427 collecting seeds and deploying the field trial. We also extend our gratitude to Riley and Dani

428 Towers for sewing the mesh seed bags.

\section{$429 \quad$ Funding}

430 This research was funded by a grant from the Australian Research Council Australian

431 (Discovery Project DP190102777)

\section{Conflicts of interest}

433 No conflicts of interests to report

\section{Ethics approval}




\section{Consent to participate}

437 Not applicable

\section{Consent for publication}

439 Not applicable

440 Availability of data and material

441 Data will be uploaded to the Dryad database if the manuscript is accepted for publication

\section{Code availability}

$443 \mathrm{R}$ code used to conduct the statistical analyses will be uploaded to the Dryad database if the

manuscript is accepted for publication

\section{Reference List}

Baker, K. S., K. J. Steadman, J. A. Plummer, D. J. Merritt, and K. W. Dixon. 2005. The changing window of conditions that promotes germination of two fire ephemerals, Actinotus leucocephalus (Apiaceae) and Tersonia cyathiflora (Gyrostemonaceae). Annals of botany 96:1225-1236.

Baskin, C. C., and J. Baskin. 2014a. Seeds: Ecology, Biogeography, and, Evolution of Dormancy and Germination. Second edition. Academic Press, San Diego.

Baskin, C. C., and J. M. Baskin. 2014b. Ecologically Meaningful Germination Studies. Pages 5-35 in C. C. Baskin and J. M. Baskin, editors. Seeds: Ecology, Biogeography, and, Evolution of Dormancy and Germination. Academic Press, San Diego.

Bell, D. T., D. P. Rokich, C. J. McChesney, and J. A. Plummer. 1995. Effects of temperature, light and gibberellic acid on the germination of seeds of 43 species native to Western Australia. Journal of Vegetation Science 6:797-806.

Bernhardt, P. 2007. Plant evolution in the Mediterranean. Quarterly Review of Biology 82:276-277.

Bouwmeester, H. J., and C. M. Karssen. 1989. Environmental factors influencing the expression of dormancy patterns in weed seeds. Annals of botany 63:113-120.

Bunker, K. V. 1994. Overcoming poor germination in Australian daisies (Asteraceae) by combinations of gibberellin, scarification, light and dark. Scientia Horticulturae 59:243-252.

Bureau of Meterology. 2020. Climate statistics for Australian locations. Bureau of Meterology.

Chesson, P. 2000a. General theory of competitive coexistence in spatially-varying environments. Theoretical Population Biology 58:211-237.

Chesson, P. 2000b. Mechanisms of maintenance of species diversity. 31:343-366.

Cowling, R. M., P. W. Rundel, B. B. Lamont, M. K. Arroyo, M. Arianoutsou, and Evolution. 1996. Plant diversity in Mediterranean-climate regions. Trends in Ecology \& Evolution 11:362-366. 
Derkx, M. P. M., and C. M. Karssen. 1993. Changing sensitivity to light and nitrate but not to gibberellins regulates seasonal dormancy patterns in Sisymbrium officinale seeds. 16:469479.

Donohue, K., R. R. d. Casas, L. Burghardt, K. Kovach, and C. G. Willis. 2010. Germination, postgermination adaptation, and species ecological ranges. Annual Review of Ecology, Evolution, and Systematics 41:293-319.

Dwyer, J. M., and T. E. Erickson. 2016. Warmer seed environments increase germination fractions in Australian winter annual plant species. Ecosphere 7:e01497.

Elston, D. A., R. Moss, T. Boulinier, C. Arrowsmith, and X. Lambin. 2001. Analysis of aggregation, a worked example: numbers of ticks on red grouse chicks. Parasitology 122:563-569.

Facelli, J. M., P. Chesson, and N. Barnes. 2005. Differences in seed biology of annual plants in arid lands: a key ingredient of the storage effect. Ecology 86:2998-3006.

Finch-Savage, W. E., and G. Leubner-Metzger. 2006. Seed dormancy and the control of germination. 171:501-523.

Flores, J., C. González-Salvatierra, and E. Jurado. 2015. Effect of light on seed germination and seedling shape of succulent species from Mexico. Journal of Plant Ecology 9:174-179.

Goldin, S. R., and M. F. Hutchinson. 2013. Coarse woody debris modifies surface soils of degraded temperate eucalypt woodlands. Plant and Soil 370:461-469.

Goldin, S. R., and M. F. Hutchinson. 2014. Coarse woody debris reduces the rate of moisture loss from surface soils of cleared temperate Australian woodlands. Soil Research 52:637-644.

Gray, A. N., and T. A. Spies. 1997. Microsite controls on tree seedling establishment in conifer forest canopy gaps. Ecology 78:2458-2473.

Gremer, J. R., S. Kimball, and D. L. Venable. 2016. Within-and among-year germination in Sonoran Desert winter annuals: bet hedging and predictive germination in a variable environment. Ecology Letters 19:1209-1218.

Gremer, J. R., and D. L. Venable. 2014. Bet hedging in desert winter annual plants: optimal germination strategies in a variable environment. Ecology Letters 17:380-387.

Grime, J. P., G. Mason, A. V. Curtis, J. Rodman, and S. R. Band. 1981. A comparative study of germination characteristics in a local flora. Journal of Ecology 69:1017-1059.

Hidayati, S. N., D. J. Merritt, S. R. Turner, K. W. Dixon, and J. L. Walck. 2019. Temporal dynamics of seedling emergence among four fire ephemerals: the interplay of after-ripening and embryo growth with smoke. Seed Science Research 29:104-114.

Hoyle, G. L., M. I. Daws, K. J. Steadman, and S. W. Adkins. 2008. Mimicking a semi-arid tropical environment achieves dormancy alleviation for seeds of Australian native Goodeniaceae and Asteraceae. Annals of botany 101:701-708.

Jaganathan, G. K. 2018. Physical dormancy alleviation and soil seed bank establishment in Cassia roxburghii is determined by soil microsite characteristics. Flora 244-245:19-23.

Karlsson, L. M., and P. Milberg. 2007. Comparing after-ripening response and germination requirements of Conyza canadensis and $C$. bonariensis (Asteraceae) through logistic functions. 47:433-441.

Kaur, J., D. Schwilk, and J. Sharma. 2020. Seed germination and plant fitness response of a narrowly endemic, rare winter annual to spatial heterogeneity in microenvironment. Plant Species Biology.

Kreft, H., and W. Jetz. 2007. Global patterns and determinants of vascular plant diversity. Proceedings of the National Academy of Sciences 104:5925-5930.

Lenth, R. 2020. emmeans: Estimated Marginal Means, aka Least-Squares Means.

Merritt, D. J., M. Kristiansen, G. R. Flematti, S. R. Turner, E. L. Ghisalberti, R. D. Trengove, and K. W. Dixon. 2006. Effects of a butenolide present in smoke on light-mediated germination of Australian Asteraceae. Seed Science Research 16:29-35.

Milberg, P., and L. Andersson. 1997. Seasonal variation in dormancy and light sensitivity in buried seeds of eight annual weed species. Canadian Journal of Botany 75:1998-2004. 
Milberg, P., L. Andersson, and K. Thompson. 2000. Large-seeded spices are less dependent on light for germination than small-seeded ones. Seed Science Research 10:99-104.

Miranda-Jácome, A., C. Montaña, and J. Fornoni. 2013. Sun/shade conditions affect recruitment and local adaptation of a columnar cactus in dry forests. Annals of botany 111:293-303.

Mittelbach, G. G., and K. L. Gross. 1984. Experimental studies of seed predation in old-fields. Oecologia 65:7-13.

Morgan, J. W. 1998. Comparative germination responses of 28 temperate grassland species. Australian Journal of Botany 46:209-219.

Plummer, J., and D. Bell. 1995. The effect of temperature, light and gibberellic acid on the germination of australian everlasting daisies (Asteraceae, tribe Inuleae). Australian Journal of Botany 43:93-102.

Pons, T. L. 2013. Light-mediated germination. CAB International, Wallingford.

$R$ Core Team. 2020. R: A language and environment for statistical computing. $R$ foundation for statistical computing, Vienna, Austria.

Rice, K. J. 1985. Responses of Erodium to varying microsites: The role of germination cueing. Ecology 66:1651-1657.

Rojas-Aréchiga, M., M. C. Mandujano, and J. K. Golubov. 2013. Seed size and photoblastism in species belonging to tribe Cacteae (Cactaceae). Journal of Plant Research 126:373-386.

RStudio Team. 2020. RStudio: Integrated Development for R (Version 1.3.1093). RStudio, Inc., Boston, MA URL http://www.rstudio.com/.

Saatkamp, A., L. Affre, T. Baumberger, P.-J. Dumas, A. Gasmi, S. Gachet, and F. Arène. 2011. Soil depth detection by seeds and diurnally fluctuating temperatures: different dynamics in 10 annual plants. Plant and Soil 349:331-340.

Schneider, C. A., W. S. Rasband, and K. W. Eliceiri. 2012. NIH Image to ImageJ: 25 years of image analysis. Nature Methods 9:671-675.

Schütz, W., P. Milberg, and B. B. Lamont. 2002. Seed dormancy, after-ripening and light requirements of four annual Asteraceae in south-western Australia. Annals of botany 90:707-714.

Scott, A. J., and J. W. Morgan. 2012. Germination strategies of annual forbs from south-eastern Australian semiarid grasslands. Australian Journal of Botany 60:340-346.

Thanos, C. A., K. Georghiou, D. J. Douma, and C. J. Marangaki. 1991. Photoinhibition of seed germination in Mediterranean maritime plants. Annals of botany 68:469-475.

Van Mourik, T. A., T. J. Stomph, and A. J. Murdoch. 2005. Why high seed densities within buried mesh bags may overestimate depletion rates of soil seed banks. Journal of Applied Ecology 42:299-305.

Vázquez-Yanes, C., and A. Orozco-Segovia. 1982. Seed germination of a tropical rain forest pioneer tree (Heliocarpus donnell-smithii) in response to diurnal fluctuation of temperature. 56:295298. 
Table 1: Intercept and regression coefficients from the probability of germination light treatment models. Intercept corresponds to the probability of germination under dark conditions while Light is change in probability under light conditions. Values are in logits where the brackets are the $95 \%$ credible interval of the posterior distribution. Bolded text indicates that the parameter estimate was considered to be significant (i.e. the credible interval did not bound zero). Species-level relative germination (RLG) is also provided where values above 0.5 indicate increased germination under light and values below 0.5 indicated decreased germination under light.

\begin{tabular}{|c|c|c|c|c|c|c|}
\hline Species & Family & Origin & $\begin{array}{l}\text { Mean seed mass } \\
(\mathrm{mg})\end{array}$ & Intercept & Light & RLG \\
\hline Arctotheca calendula (L.) & Asteraceae & $\mathrm{E}$ & 1.49 & & & \\
\hline K.Lewin & & & & $-0.90(-1.45,-0.37)$ & $-0.24(-0.68,0.20)$ & 0.46 \\
\hline $\begin{array}{l}\text { Daucus glochidiatus } \\
\text { (Labill.) Fisch., C.A.Mey. }\end{array}$ & Apiaceae & $\mathrm{N}$ & 2.72 & & & \\
\hline \& Avé-Lall & & & & $2.80(2.25,3.53)$ & $0.86(0.06,1.65)$ & 0.51 \\
\hline Goodenia berardiana & Goodeniaceae & $\mathrm{N}$ & 2.47 & & & \\
\hline (Gaudich.) Carolin & & & & $-1.17(-1.72,-0.66)$ & $5.66(4.78,6.70)$ & 0.81 \\
\hline Hyalosperma glutinosum & Asteraceae & $\mathrm{N}$ & 0.91 & & & \\
\hline Steetz subsp. Glutinosum & & & & $0.53(-0.17,1.23)$ & $0.70(-0.13,1.60)$ & 0.55 \\
\hline Hypochaeris glabra L. & Asteraceae & $\mathrm{E}$ & 0.42 & $3.35(2.62,4.31)$ & $0.59(-0.35,1.60)$ & 0.50 \\
\hline Lawrencella rosea Lindl. & Asteraceae & $\mathrm{N}$ & 1.39 & $-1.60(-2.17,-1.07)$ & $3.20(2.68,3.83)$ & 0.83 \\
\hline
\end{tabular}


Plantago debilis $\mathrm{R}$. Br. Plantaginaceae

$\mathrm{N}$

Podolepis aristata Benth. Asteraceae

subsp. aristata

Schoenia cassiniana

Asteraceae

(Gaudich.) Steetz

Trachymene cyanopetala

Araliaceae

(F.Muell.) Benth

Trachymene ornata

Araliaceae

(Endl.) Druce

Velleia rosea $\mathrm{S}$. Moore

Goodeniaceae

$\mathrm{N}$

$\mathrm{N}$

$\mathrm{N}$
0.62

0.21

3.00

$-0.66(-1.07,-0.25)$

$1.79(1.29,2.33)$

0.69

2.09

$-0.46(-1.06,0.12)$

$0.11(-0.25,0.46)$

0.52

1.80

558

559

$\begin{array}{lll}-1.93(-2.36,-1.52) & 0.75(0.26,1.25) & 0.65 \\ -1.68(-2.47,-0.91) & 5.15(4.12,6.36) & 0.86\end{array}$


Table 2: Intercept and regression coefficients from the maximum germinability environment models. Values in brackets are the 95\% credible interval of the posterior distribution. Bolded text indicates that the parameter estimate was considered to be significant (i.e. the credible interval did not bound zero). Values are in logits and are in standardised units for scaled sqrt(Canopy cover). The species-level median of maximum germination is also provided where the values in brackets are the lower and upper 95\% quantiles.

\begin{tabular}{lllll}
\hline Species & Median maximum & Intercept & sqrt(Canopy cover) & CWD \\
& germination & & & \\
\hline Arctotheca calendula & $0.34(0.09,0.74)$ & $-0.71(-1.48,0.02)$ & $0.35(-0.20,0.91)$ & $0.04(-1.03,1.14)$ \\
Daucus glochidiatus & $1.00(0.92,1.00)$ & $\mathbf{4 . 0 9}(\mathbf{2 . 9 4}, \mathbf{5 . 8 7})$ & $0.17(-0.91,1.24)$ & $0.70(-1.22,2.96)$ \\
Goodenia berardiana & $1.00(0.91,1.00)$ & $\mathbf{5 . 5 1}(\mathbf{3 . 5 4}, \mathbf{8 . 9 1})$ & $1.17(-0.31,3.38)$ & $-0.05(-2.9,3.21)$ \\
Hyalosperma glutinosum & $0.86(0.45,1.00)$ & $\mathbf{1 . 5 5}(\mathbf{0 . 5 4}, \mathbf{2 . 6 9})$ & $-0.11(-0.87,0.67)$ & $-0.10(-1.62,1.41)$ \\
Hypochaeris glabra & $1.00(0.91,1.00)$ & $\mathbf{5 . 0 7}(\mathbf{3 . 1 2}, \mathbf{8 . 6 8})$ & $-0.82(-3.16,0.65)$ & $0.56(-2.58,3.73)$ \\
Lawrencella rosea & $0.81(0.57,1.00)$ & $\mathbf{1 . 2 2}(\mathbf{0 . 4 0}, \mathbf{2 . 0 9})$ & $-0.02(-0.62,0.60)$ & $0.73(-0.47,2.06)$ \\
Plantago debilis & $0.77(0.40,1.00)$ & $\mathbf{1 . 0 0}(\mathbf{0 . 1 3}, \mathbf{1 . 9 4})$ & $0.62(-0.06,1.34)$ & $0.73(-0.53,2.10)$ \\
Podolepis aristata & $0.33(0.10,0.76)$ & $-0.62(-1.40,0.15)$ & $\mathbf{- 0 . 5 7}(\mathbf{- 1 . 1 8}, \mathbf{- 0 . 0 5})$ & $-0.17(-1.25,0.91)$ \\
Schoenia cassiniana & $0.77(0.47,0.95)$ & $\mathbf{1 . 0 7}(\mathbf{0 . 2 6}, \mathbf{1 . 9 1})$ & $0.04(-0.58,0.64)$ & $0.23(-1.02,1.44)$ \\
Trachymene cyanopetala & $0.50(0.08,0.79)$ & $0.24(-0.55,1.03)$ & $-0.34(-0.93,0.21)$ & $-0.69(-1.81,0.47)$
\end{tabular}


Table 3: Intercept and regression coefficients from the probability of germination $\sim$ light $*$ environment models. Values in brackets are the $95 \%$ credible interval of the posterior distribution. Bolded text indicates that the parameter estimate was considered to be significant (i.e. the credible interval did not bound zero).

Values are in logits and are in standardised units for sqrt(Canopy cover).

\begin{tabular}{|c|c|c|c|c|c|c|}
\hline Species & Intercept & Light & sqrt(Canopy cover) & CWD & $\begin{array}{l}\text { Light*sqrt(Canopy } \\
\text { cover) }\end{array}$ & Light*CWD \\
\hline Arctotheca calendula & $-0.88(-1.72,-0.06)$ & $-0.22(-1.35,0.93)$ & $0.48(-0.11,1.11)$ & $-0.06(-1.19,1.08)$ & $-0.39(-1.26,0.46)$ & $-0.02(-1.66,1.62)$ \\
\hline Daucus glochidiatus & $3.07(2.20,4.11)$ & $0.75(-0.64,2.14)$ & $-0.26(-0.91,0.38)$ & $-0.38(-1.64,0.87)$ & $0.54(-0.42,1.54)$ & $0.27(-1.72,2.23)$ \\
\hline Goodenia berardiana & $-0.63(-1.31,0.01)$ & $5.57(4.03,7.45)$ & $-0.26(-0.75,0.23)$ & $-1.10(-2.10,-0.17)$ & $1.18(0.08,2.47)$ & $0.97(-1.22,3.23)$ \\
\hline Hyalosperma glutinosum & $0.56(-0.51,1.68)$ & $0.71(-0.83,2.26)$ & $-0.32(-1.08,0.45)$ & $-0.03(-1.56,1.47)$ & $0.42(-0.76,1.57)$ & $0.04(-2.15,2.19)$ \\
\hline Hypochaeris glabra & $3.39(2.34,4.65)$ & $0.40(-1.24,2.03)$ & $-0.07(-0.95,0.77)$ & $0.04(-1.63,1.75)$ & $-0.33(-1.77,1.00)$ & $0.89(-1.84,3.61)$ \\
\hline Lawrencella rosea & $-2.14(-3.05,-1.31)$ & $3.38(2.19,4.67)$ & $-0.06(-0.65,0.53)$ & $0.91(-0.22,2.1)$ & $0.04(-0.81,0.93)$ & $-0.15(-1.83,1.52)$ \\
\hline Plantago debilis & $0.14(-0.84,1.14)$ & $0.48(-0.98,1.94)$ & $0.21(-0.59,1.01)$ & $1.08(-0.36,2.5)$ & $0.45(-0.69,1.58)$ & $-0.91(-3.04,1.18)$ \\
\hline Podolepis aristata & $-1.21(-2.15,-0.30)$ & $-0.63(-2.04,0.74)$ & $-0.73(-1.41,-0.12)$ & $-0.52(-1.81,0.70)$ & $0.28(-0.68,1.22)$ & $1.39(-0.46,3.27)$ \\
\hline Schoenia cassiniana & $-0.84(-1.48,-0.24)$ & $1.84(0.98,2.79)$ & $0.11(-0.35,0.56)$ & $0.35(-0.54,1.23)$ & $-0.05(-0.70,0.59)$ & $-0.07(-1.37,1.22)$ \\
\hline Trachymene cyanopetala & $0.01(-0.81,0.82)$ & $-0.11(-1.29,1.08)$ & $-0.2(-0.79,0.42)$ & $-0.94(-2.11,0.21)$ & $-0.17(-1.05,0.67)$ & $0.46(-1.20,2.14)$ \\
\hline Trachymene ornata & $-1.68(-2.24,-1.14)$ & $0.55(-0.19,1.31)$ & $-0.26(-0.68,0.13)$ & $-0.53(-1.34,0.25)$ & $-0.08(-0.62,0.48)$ & $0.41(-0.68,1.53)$ \\
\hline
\end{tabular}


562 Figure 1: Adjusted germination percentages for 12 focal species in light (12h diurnal light) or 563 dark conditions. Boxes represent the interquartile range and median and the whiskers

564 represent the range. Significant differences in the probability of germination between light

565 and dark conditions in the binomial mixed-effects model are represented by *. Species-level 566 mean fill rates are presented in grey at the bottom of each panel.

567 
568 Figure 2: Adjusted maximum germination percentages for three focal species retrieved from 569 patches across a gradient of scaled sqrt(Seed bank canopy cover). Solid lines represent the 570 fitted relationship while the grey fields represent the $95 \%$ credible interval around the fitted 571 relationship. Patch-level seed fill rates are presented in grey at the top of the panel. ${ }^{\mathrm{a}}$ and ${ }^{\mathrm{b}}$ 572 indicates that the noted fill rate is instead the mean fill rate for canopy cover values of zero (5731.41 on the scale of the x-axis) and canopy cover values of $\sim 34 \%$ and $36 \%(0.75$ and 0.83 on 574 the scale of the $\mathrm{x}$-axis), respectively, to improve visual clarity. 

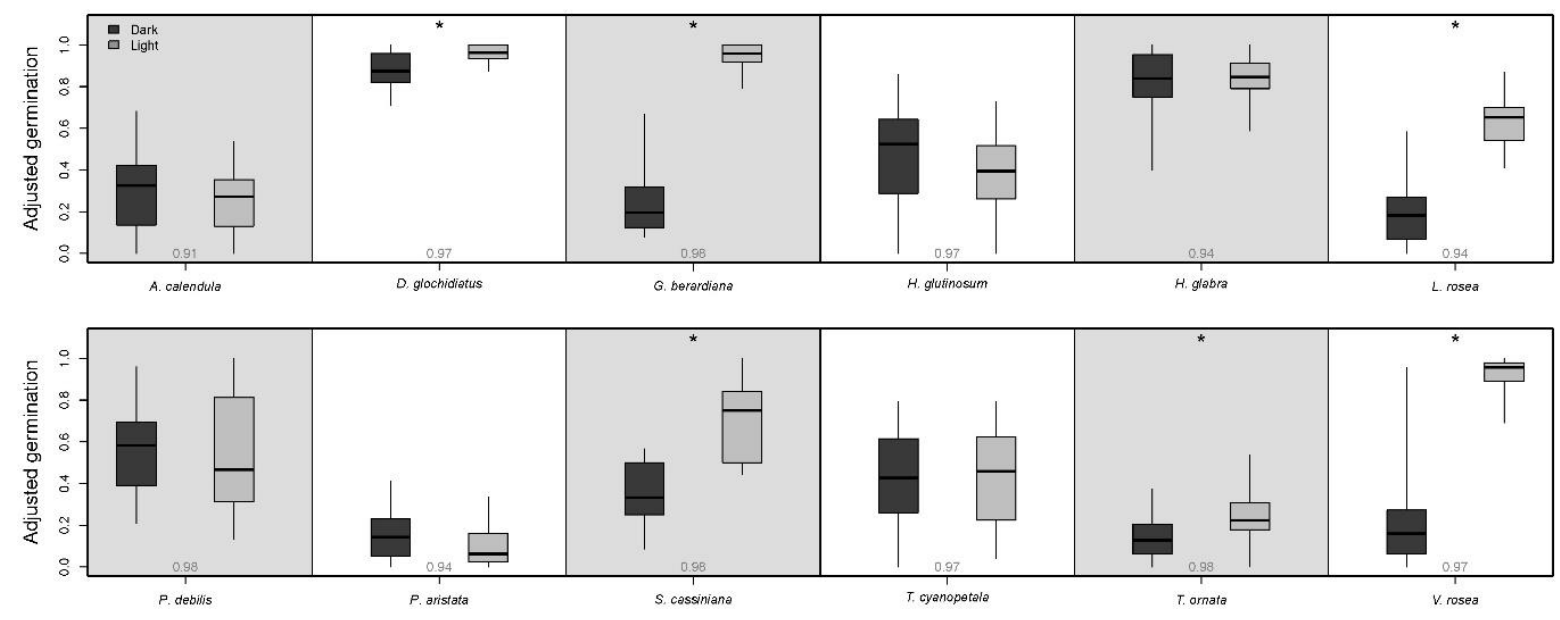

Figure 1 

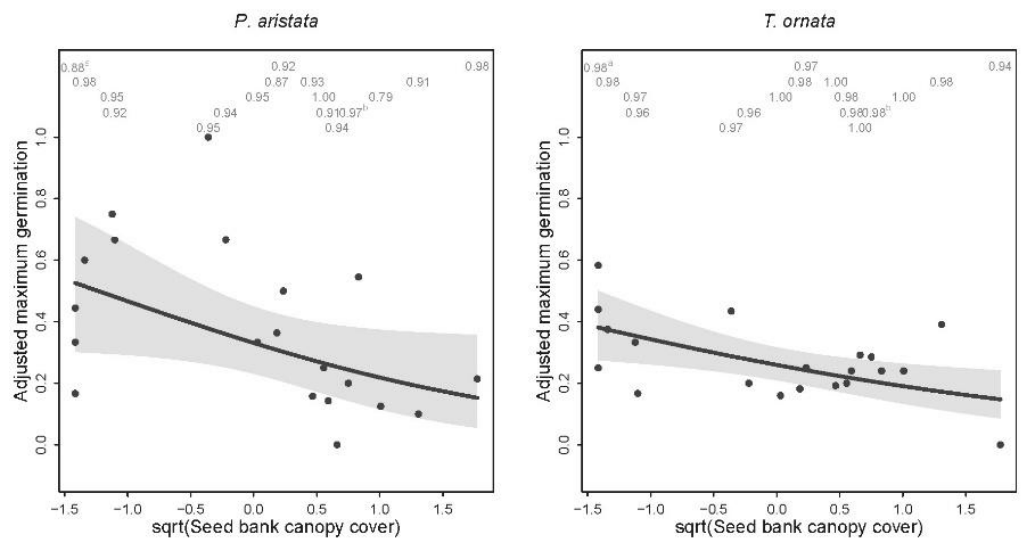

Figure 2 
Figures
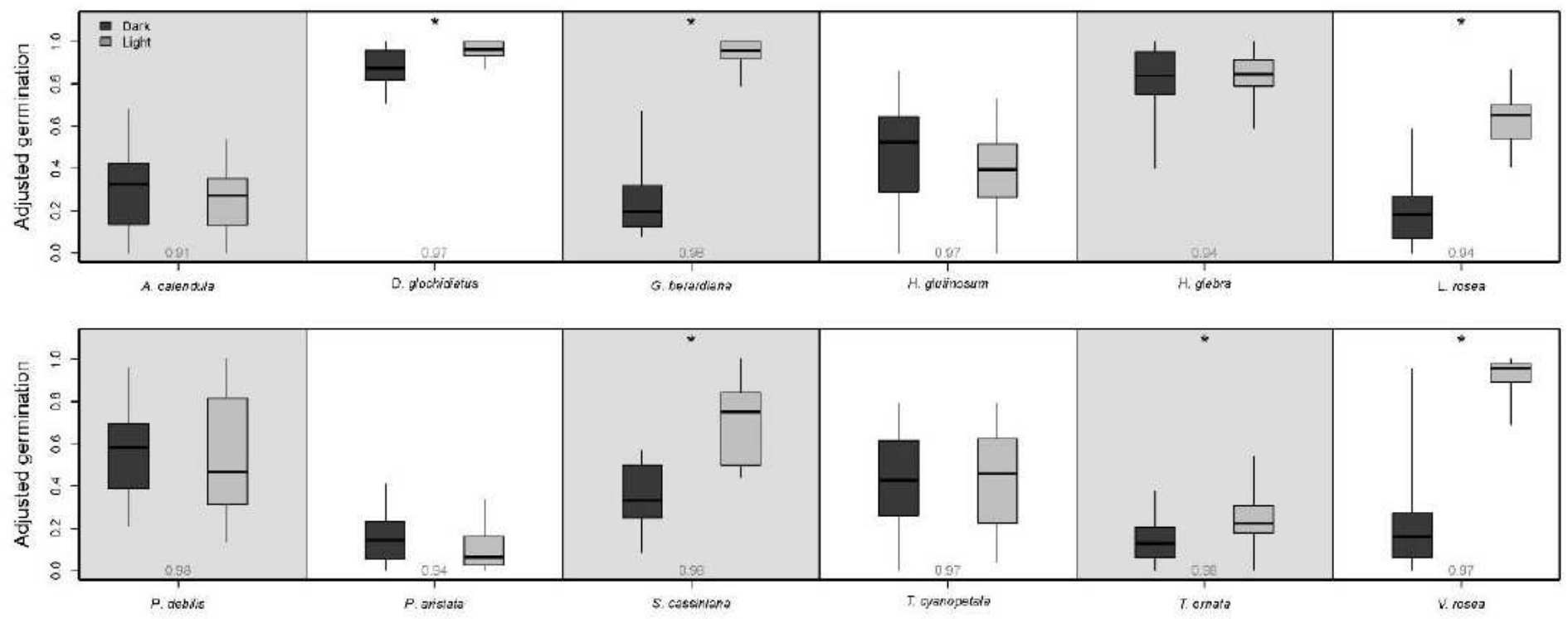

Figure 1

Adjusted germination percentages for 12 focal species in light (12h diurnal light) or dark conditions. Boxes represent the interquartile range and median and the whiskers represent the range. Significant differences in the probability of germination between light and dark conditions in the binomial mixedeffects model are represented by *. Species-level mean fill rates are presented in grey at the bottom of each panel.

P. aristata

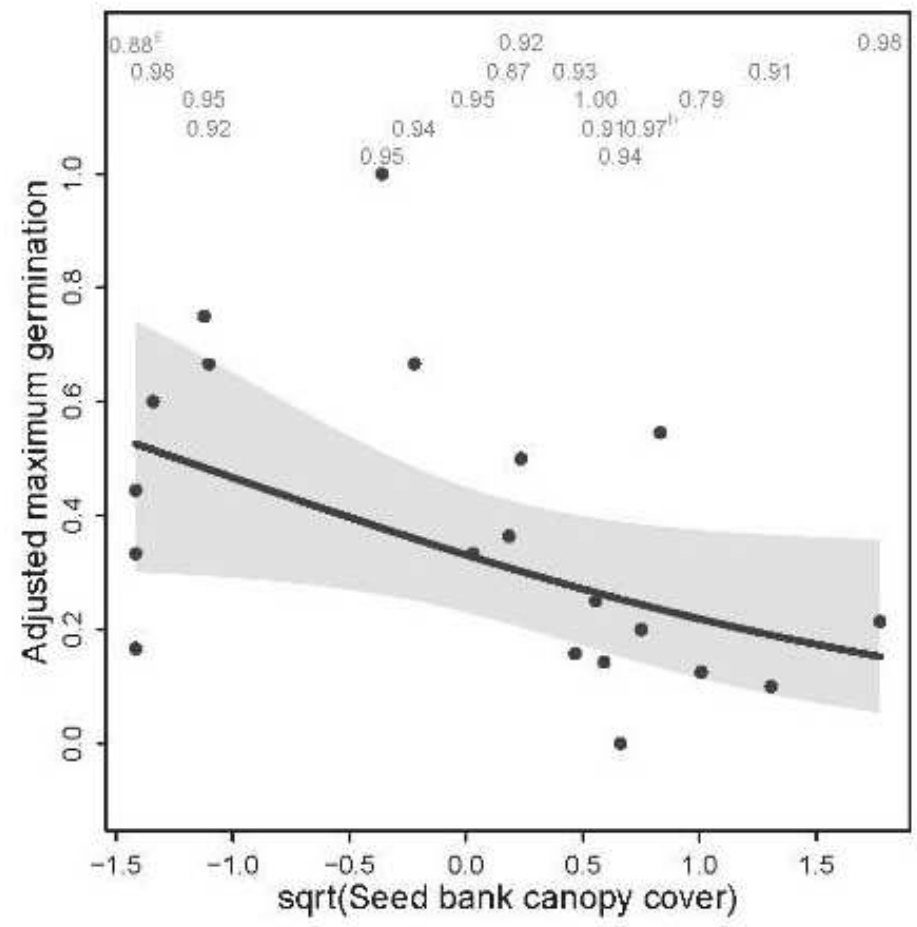

T. ornata

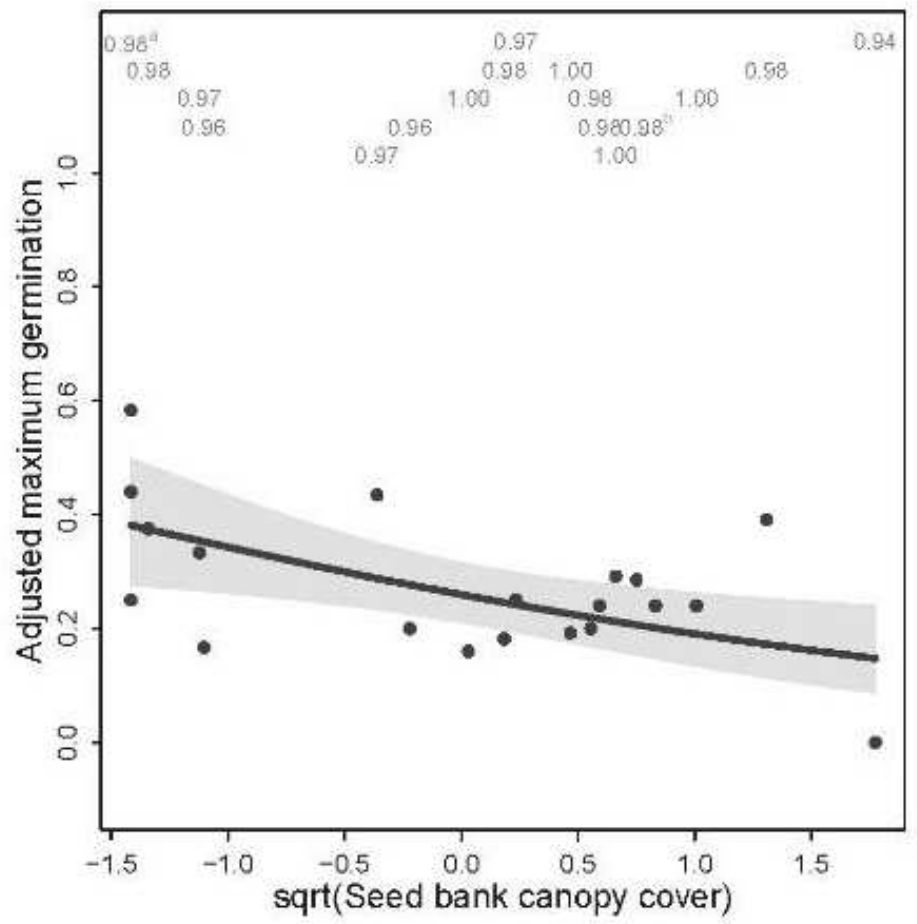




\section{Figure 2}

Adjusted maximum germination percentages for three focal species retrieved from patches across a gradient of scaled sqrt(Seed bank canopy cover). Solid lines represent the fitted relationship while the grey fields represent the $95 \%$ credible interval around the fitted relationship. Patch-level seed fill rates are presented in grey at the top of the panel. $a$ and $b$ indicates that the noted fill rate is instead the mean fill rate for canopy cover values of zero (-1.41 on the scale of the x-axis) and canopy cover values of $~ 34 \%$ and $36 \%$ ( 0.75 and 0.83 on the scale of the $x$-axis), respectively, to improve visual clarity.

\section{Supplementary Files}

This is a list of supplementary files associated with this preprint. Click to download.

- Oecologiasupplementaryinformation.pdf 